\title{
NEOLIT I EPOKA BRĄZU W EUROPIE ŚRODKOWEJ W ŚWIETLE POZNAŃSKICH BADAŃ NA CMENTARZYSKACH
}

\author{
NEOLITHIC AND BRONZE AGE IN CENTRAL EUROPE \\ IN THE LIGHT OF INVESTIGATIONS OF CEMETERIES \\ BY RESEARCHERS FROM POZNAŃ
}

\author{
Lukasz Pospieszny \\ Instytut Archeologii i Etnologii PAN \\ Laboratorium Bio- i Archeometrii \\ ul. Rubież 46, 61-612 Poznań, Poland
}

\begin{abstract}
The article discusses the selected research projects, carried out by archaeologists from Poznań, which focus on the study of the Late Neolithic and the Early and Middle Bronze Age cemeteries. The methodology applied and the results of the excavations, geophysical and remote sensing research of barrow cemeteries in Wielkopolska (Poland) and Maramureş (Romania) have been presented. The preliminary results of isotopic analyses of human remains from Poland and Hungary have been characterised.
\end{abstract}

\section{WPROWADZENIE}

Od początku funkcjonowania Instytut Prahistorii UAM prowadził intensywne studia nad obrzędowością pogrzebową społeczeństw pradziejowych i wczesnohistorycznych. Osobiste zaangażowanie prof. J. Kostrzewskiego doprowadziło chociażby do realizacji pierwszych planowanych badań wykopaliskowych na reperowym cmentarzysku kultury mogiłowej (dalej: KM) w Smoszewie k. Krotoszyna ${ }^{1}$. Przyniosły one wyniki, które na wiele lat stały się punktem odniesienia w studiach nad środkową epoką brązu w południowej Wielkopolsce. Zespół archeologów skupionych wokół Pracowni Archeologii Śródziemnomorskiej Epoki Brązu (dalej: Pracowni) ma w swoim programie badawczym projekty, które z jednej strony nawiązu-

\footnotetext{
${ }^{1}$ Kostrzewski 1922-1924.
} 
ją do doświadczeń prahistoryków poznańskich w zakresie badań na cmentarzyskach, a z drugiej - pracują na ten dorobek poprzez wdrażanie nowej metodyki oraz poszerzanie zasięgu zainteresowania o Kotlinę Karpacką i Egeę.

\section{SPOŁECZEŃSTWA KULTURY JAMOWEJ NA NIZINIE WĘGIERSKIEJ}

W początkach III tys. przed Chr. na obszarze Kotliny Karpackiej pojawiły się społeczeństwa identyfikowane dziś z wczesną kulturą jamową (dalej: KJ). Powszechnie przyjmuje się, że były to stosunkowo niewielkie społeczności pasterskie, przemieszczające się wzdłuż pasa roślinności stepowej, sięgającego aż do obszaru puszty węgierskiej ${ }^{2}$. Ten tzw. korytarz stepowy rozciągał się od wybrzeży Morza Czarnego w górę biegu Dunaju i Cisy. Choć wyznaczony kurhanami zasięg osadnictwa wczenojamowego jest bardzo zwarty i ograniczony warunkami środowiskowymi, coraz częściej wskazuje się na ważną rolę, jaką odegrały społeczeństwa KJ w zainicjowaniu wczesnej epoki brązu w całej Europie Środkowej ${ }^{3}$. Co więcej, rozproszone przykłady obecności lub oddziaływań „,stepowych” znane są także z obszarów bałkańskich, czego najlepszym przykładem są bogato wyposażone kurhany Mała i Wielka Gruda w Czarnogórze ${ }^{4}$. Możliwe również, że srebro, z którego wykonywano zausznice odkrywane w grobach KJ, importowano z Egei lub Wysp Cykladzkich $^{5}$. Wpływy ,wczesnojamowe" miały doprowadzić do upowszechnienia się w Europie wielu nowych wzorców ekonomicznych. Polegały one głównie na inwestowaniu nadwyżek w dobra ruchome - przede wszystkim w bydło oraz metale, które poprzez rytuały pogrzebowe były wyłączane $\mathrm{z}$ obiegu i deponowane w grobach $^{6}$. Konsekwencją transformacji w obrębie gospodarki było nasilenie się procesów indywidualizacji i hierarchizacji społecznej. Ponieważ zjawiska te zachodziły synchronicznie w wielu regionach poza Kotliną Karpacką, nasuwa się pytanie, czy każdorazowo były one wynikiem oddziaływań ze strony społeczeństw „wczesnojamowych"? Pierwszym problemem pojawiającym się przy próbie odpowiedzi na to pytanie są nieścisłości w chronologii bezwzględnej KJ i trudności w ich synchronizacji z innymi kulturami późnoneolitycznymi. Konkretyzując: większość dat ${ }^{14} \mathrm{C}$ wykonano na wczesnym etapie rozwoju metody radiowęglowej oraz z użyciem próbek długożyciowych ${ }^{7}$. W efekcie nie jest możliwe określenie wieku absolutnego datowanych zespołów grobowych według współczesnych standardów dokładności

\footnotetext{
${ }^{2}$ Horváth 2011.

${ }^{3}$ Harrison, Heyd 2007.

${ }^{4}$ Primas 1996.

${ }^{5}$ Jovanović 1993.

${ }^{6}$ Kristiansen 1998, 394, 412, 413.

${ }^{7}$ Pospieszny 2012.
} 
metody ${ }^{14} \mathrm{C}$, zwłaszcza po wprowadzeniu techniki AMS (Accelerator Mass Spectrometry).

Wypełniając umowę między UAM a Węgierską Akademią Nauk w Budapeszcie, w ramach współpracy z tamtejszym Instytutem Archeologii, Pracownia zaangażowana jest w projekt datowania serii szczątków ludzkich pochodzących z grobów podkurhanowych z obszaru puszty. Równolegle prowadzone są również pilotażowe badania izotopowe ukierunkowane na rekonstrukcję diety i mobilności osobniczej. Otrzymane do tej pory wyniki pozwoliły dokonać pierwszego na tak dużą skalę uporządkowania chronologii absolutnej węgierskiej $\mathrm{KJ}^{8}$. Stwarza to perspektywy bardziej szczegółowych studiów porównawczych nad początkami epoki brązu w Kotlinie Karpackiej i na obszarach ościennych, w tym na ziemiach polskich.

\section{SCHYŁEK NEOLITU I WCZESNA EPOKA BRĄZU NA ZIEMIACH POLSKICH}

$\mathrm{Na}$ większą skalę program badań izotopowych, obejmujących oprócz datowania metodą ${ }^{14} \mathrm{C}$ także pomiary izotopów węgla, azotu, strontu i tlenu, przeprowadzono dla późnoneolitycznych i wczesnobrązowych zespołów grobowych z obszaru Polski, ze szczególnym uwzględnieniem Niżu Polskiego. Analizy przeprowadzono w ramach dwóch projektów, w które zaangażowani byli archeolodzy z Pracowni. Pierwszy z nich sfinansowano z grantu Ministerstwa Nauki i Szkolnictwa Wyższego 9 . Drugi, zatytułowany ,,Travels, transmissions and transformations in the 3rd and 2nd millennium BC in northern Europe: the rise of Bronze Age societies"10, finansowany jest ze środków European Research Council Advanced Grant, a kieruje nim profesor K. Kristiansen z Uniwersytetu w Göteborgu ${ }^{11}$.

Badaniami w obu, uzupełniających się, projektach objęto zespoły grobowe reprezentujące kultury: ceramiki sznurowej, iwieńską i unietycką. Wytyczono w nich wiele celów.

Najważniejszy z nich to ustalenie lub korekta wieku absolutnego pochówków o podstawowym znaczeniu dla zrozumienia dynamiki zmian społeczno-ekonomicznych na przełomie neolitu i epoki brązu w Polsce oraz w całej strefie bałtyckiej ${ }^{12}$. W sumie dla obszarów polskich uzyskano 25 nowych dat radiowęglowych. $\mathrm{Z}$ realizacją tego zadania łączy się problem postarzenia części dat ${ }^{14} \mathrm{C}$ w rezultacie efektu

\footnotetext{
${ }^{8}$ Horváth et al. 2013.

${ }^{9}$ Projekt nr N N 109287 137, kierowany przez prof. J. Czebreszuka z IP UAM i zrealizowany przez dr. Ł. Pospiesznego z IP UAM (obecnie IAE PAN).

${ }^{10}$ Projekt nr 269442.

${ }^{11}$ Wykonawcami ze strony Pracowni są prof. J. Czebreszuk z IP UAM oraz dr Ł. Pospieszny z IAE PAN.

${ }^{12}$ Por. np. Czebreszuk 1996, 2001; Kristiansen, Larsson 2005; Pospieszny 2009, 2012.
} 
rezerwuarowego. Ryzkiem otrzymania zbyt wczesnych oznaczeń radiowęglowych obciążone są próbki pochodzące od ludzi i zwierząt, w których diecie duży udział miały organizmy słodkowodne ${ }^{13}$. Miarą efektu rezerwuarowego jest różnica wieku radiowęglowego próbki postarzonej oraz wieku próbki nieobciążonej ryzykiem postarzenia. Pośrednio na zachodzenie efektu rezerwuarowego może wskazywać rekonstrukcja diety, oparta na analizach stabilnych izotopów węgla $\left(\delta^{13} \mathrm{C}\right)$ i azotu $\left(\delta^{15} \mathrm{~N}\right)$. Użycie obu technik pozwoliło m.in. na wyjaśnienie przyczyny zbyt wczesnego wieku radiowęglowego szczątków ludzkich z późnoneolitycznego cmentarzyska na stan. 10 w Ząbiu na Pojezierzu Olsztyńskim ${ }^{14}$.

Rekonstrukcja diety ma również szerszy cel, jakim jest rozpoznanie różnic w zwyczajach żywieniowych w wybranych populacjach z przełomu epok oraz między nimi. Wstępne wyniki pokazują wzrost zróżnicowania źródeł pokarmu u schyłku neolitu. Podobną zależność obserwuje się w wielu rejonach Europy - i jest ona tłumaczona zmianami gospodarczymi, zmierzającymi do coraz większej specjalizacji i hierarchizacji społecznej ${ }^{15}$.

Celem, który wymagał zastosowania analiz izotopów strontu $\left({ }^{87} \mathrm{Sr} /{ }^{86} \mathrm{Sr}\right)$ i tlenu $\left({ }^{18} \mathrm{O} /{ }^{16} \mathrm{O}\right)$, była rekonstrukcja mobilności osobniczej w wybranych populacjach ludzkich z III i początków II tys. przed Chr. Jednym z pierwszych wyników było stwierdzenie najstarszego jak dotąd w Polsce przykładu migracji w skali życia jednego człowieka. Był nim mężczyzna pochowany we wczesnosznurowym grobie podkurhanowym w Kruszynie, stan. 13, na Kujawach ${ }^{16}$.

Zarówno w przypadku rekonstrukcji diety, jak i mobilności osobniczej, kluczowe znaczenie ma przeanalizowanie odpowiednio licznej serii próbek kości zwierzęcych. Umożliwia to zrekonstruowanie lokalnej sieci troficznej oraz ustalenie zakresów wartości izotopów strontu i tlenu, uwarunkowanych środowiskowo i typowych dla danego regionu. Jednostkowy charakter dotychczas przeprowadzonych badań powoduje, że są one mało reprezentatywne. Następne lata powinny przynieść przyrost tego rodzaju danych, co spowoduje, że staną się one podstawą bardziej uprawomocnionych interpretacji.

\section{CMENTARZYSKA KURHANOWE ZE ŚRODKOWEJ EPOKI BRĄZU W RUMUNII I POLSCE}

Ważny obszarem zaangażowania badaczy skupionych wokół Pracowni są badania, zarówno nieinwazyjne, jak i wykopaliskowe, nekropolii kurhanowych. Na

\footnotetext{
${ }^{13}$ Lanting, van der Plicht 1998.

${ }^{14}$ Pospieszny 2014; autor dziękuje dr. Adamowi Walusiowi i dr. Dariuszowi Manasterskiemu z Instytutu Archeologii UW za udostępnienie dokumentacji i materiałów do badań.

${ }^{15} \mathrm{~Np}$. Asam, Grupe, Peters 2006.

${ }^{16}$ Pospieszny, Sobkowiak-Tabaka, Frei et al. 2014.
} 
omówienie zasługują zwłaszcza dwa projekty realizowane we współpracy międzynarodowej. Pierwszy z nich dotyczy stanowiska w Lăpuş w Maramureszu rumuńskim.

Badania w Rumunii kierowane są przez archeologów z Institut für Vor- und Frühgeschichtliche Archäologie und Provinzialrömische Archäologie der Ludwig-Maximilians-Universität w Monachium (LMU), we współpracy z Muzeul Judeţean de Istorie şi Arheologie Maramureş w Baia Mare. Na mocy umowy o współpracy między UAM i LMU od 2008 r. w projekt zaangażowani są archeolodzy z Poznania, których zadaniem jest opracowanie szczegółowego modelu wysokościowego stanowiska oraz wykonanie prospekcji magnetometrycznej wszystkich zarejestrowanych na stanowisku nasypów oraz ich otoczenia.

Stanowisko w Lăpuş znane jest od dawna w literaturze jako przykład rozległej nekropolii ze środkowej epoki brązu (XIII stulecie przed Chr.) ${ }^{17}$. Pierwsze wykopaliska prowadzono na nim już w końcu XIX w. Rozpoczęte w 2008 r. badania wykopaliskowe i geofizyczne nasypu $\mathrm{nr} 26$ ujawniły, że różni się on diametralnie od przebadanych wcześniej kurhanów. Wewnątrz nie odkryto typowego, okrągłego płaszcza kamiennego, kryjącego centralnie usytuowany pochówek. Przeciwnie zawierał on prostokątną $\mathrm{w}$ zarysie, wielofazową konstrukcję $\mathrm{w}$ typie halowego budynku słupowego, któremu towarzyszą kamienne rampy i depozyty ceramiki oraz przepalonych szczątków zwierzęcych. Badacze niemieccy dopatrują się analogii do odkrytej budowli w megaronach, stanowiących centralne obiekty w pałacach mykeńskich $^{18}$.

Należy podkreślić, że przedstawiony powyżej skrótowo projekt badawczy jest wzorcowym przykładem zastosowania metody geofizycznej w badaniach archeologicznych. Przeprowadzenie prospekcji geofizycznej pozwoliło na uzyskanie bardzo szczegółowego obrazu nawarstwień, ułatwiającego planowanie prac wykopaliskowych na bardzo skomplikowanym, wielkowarstwowym obiekcie. Wyniki wykopalisk stały się jednocześnie rodzajem klucza interpretacyjnego, bez którego zrozumienie rezultatów badań magnetometrycznych pozostałych nasypów byłoby niezwykle trudne.

Drugi projekt, a w zasadzie grupa projektów realizowana jest na obszarze południowej Wielkopolski i koncentruje się wokół problematyki cmentarzysk kurhanowych KM i ich zaplecza osadniczego. Zainicjowane zostały one badaniami wspomnianego we wstępie cmentarzyska w Smoszewie, stan. 1, położonego w obrębie Lasu Krotoszyn, części Dąbrowy Krotoszyńskiej, charakteryzującej się bardzo starym drzewostanem. Jego wiek sięga 150 lat, a miejscami przekracza nawet dwa stulecia. Wyłącznie tych obszarów spod uprawy w okresie intensywnego rozwoju rolnictwa przyczyniło się do wyjątkowo dobrego zachowania reliktów krajobrazu kulturowego z epoki brązu.

\footnotetext{
${ }^{17}$ Kacsó, Metzner-Nebelsick, Nebelsick 2011.

${ }^{18}$ Metzner-Nebelsick, Kacsó, Nebelsick 2010.
} 
W 2008 r. wykonano szczegółowe pomiary wysokościowe nekropolii smoszewskiej w granicach wyznaczonych zasięgiem planów z lat 20. XX w. Następnym krokiem była prospekcja geofizyczna kurhanu $\mathrm{nr} 15$, z wykorzystaniem metody magnetometrycznej i elektrooporowej. Ujawniły one zły stan zachowania obiektu, niszczonego przez wkopy rabunkowe i zagrożonego procesami erozyjnymi ${ }^{19}$. Podjęto wówczas decyzję o przeprowadzeniu ratowniczych badań wykopaliskowych. Prace badawcze zrealizowano w latach 2009-2011 ${ }^{20}$, we współpracy z Uniwersytetem im. Christiana-Albrechta w Kilonii (Niemcy) i Uniwersytetem w Aarhus (Dania), przy wsparciu Wojewódzkiego Urzędu Ochrony Zabytków w Poznaniu, Nadleśnictwa Krotoszyn oraz Urzędu Miejskiego w Krotoszynie. Partnerstwo z miastem zostało sformalizowane zawarciem umowy o współpracy z UAM w 2009 r. Pod nasypem kurhanu odsłonięto złożoną konstrukcję kamienną, z centralnie położoną komorą grobową. Pracom terenowym towarzyszyła kwerenda archiwów oraz zbiorów muzealnych. Przyniosła ona „odkrycie” niepublikowanej dokumentacji jednego z kurhanów oraz zabytków brązowych i węgli drzewnych wydobytych w trakcie wykopalisk w latach 20. i 60.

Nekropolia na stanowisku nr 1 jest stosunkowo łatwo dostępna do badań ze względu na porastającą ją świetlistą dąbrowę. Inaczej przestawia się sytuacja $\mathrm{z}$ innymi cmentarzyskami rozsianymi po całym lesie krotoszyńskim. Część z nich porośnięta jest przez młode, gęste drzewostany, co poważnie utrudnia ich wykrycie i zadokumentowanie. Aby zinwentaryzować wszystkie kurhany znajdujące się w Lesie Krotoszyn oraz ocenić ich stan zachowania i zidentyfikować potencjalne zagrożenia, przeprowadzono lotniczy skaning laserowy (ang. Airborne Laser Scanning), który objął powierzchnię $62,29 \mathrm{~km}^{2}$. Badania teledetekcyjne były częścią projektu „Modelowe badania nieinwazyjne obszarów leśnych - Las Krotoszyn”, finansowanego ze środków Ministerstwa Kultury i Dziedzictwa Narodowego, uzyskanych przez Pracownię w ramach konkursu Narodowego Instytutu Dziedzictwa. Program badawczy obejmował również weryfikację terenową potencjalnych kurhanów. W efekcie uzyskano informację o 124 kurhanach, z których tylko ok. 30 znanych było dotąd w literaturze i zasobach Archeologicznego Zdjęcia Polski. Dane zgromadzone w procesie identyfikacji, weryfikacji i dokumentacji grobów kurhanowych i innych, mniej licznych, obiektów archeologicznych o własnej formie krajobrazowej zebrano w udostępnianej online przez Narodowy Instytut Dziedzictwa referencyjnej bazie danych.

W ramach projektu wykonano także badania magnetometryczne na całym stanowisku nr 1. Przyniosły one bardzo dobre rezultaty, ponieważ część materiału ka-

\footnotetext{
${ }^{19}$ Jaeger, Pospieszny 2011a, 2011 b.

${ }^{20}$ Cwaliński 2010; Kneisel, Jaeger, Pospieszny, Holst 2010; Kasprolewicz 2013; Niebieszczeński 2010; Cwaliński, Niebieszczański 2012; Szumotalska 2012; Czebreszuk, Jaeger, Pospieszny et al. 2014a, 2014b, 2014c.
} 
miennego, którego użyto do budowy kurhanów, charakteryzuje się podwyższoną podatnością magnetyczną. W efekcie kontrastują one silnie na tle piaszczystego podłoża i pozwalają na określnie rozmiarów wewnętrznej konstrukcji obiektów, których nasypy uległy w ciągu wieków zniwelowaniu i zniekształceniu w wyniku procesów erozji. Podobnie jak w przypadku stanowiska w Lăpuş, wyniki prac wykopaliskowych pojedynczego kurhanu, badanego wcześniej z użyciem metod nieinwazyjnych, ułatwiły zrozumienie obrazu geofizycznego całej nekropolii.

Dane zebrane w ramach projektu dotyczącego całego Lasu Krotoszyn są obecnie wykorzystywane w nowym programie badawczym, finansowanym ze środków Narodowego Centrum Nauki ${ }^{21}$.

Zainicjowane ,powrotem” do Smoszewa studia nad KM w Lesie Krotoszyn poszerzone zostały z czasem o cały tzw. krotoszyńsko-ostrowski mikroregion osadniczy, stanowiący w epoce brązu ważny element pogranicza kulturowego Śląska i Wielkopolski. W 2013 r. przeprowadzono badania nieinwazyjne dwóch osad otwartych w Gliśnicy i Nabyszycach. W Gliśnicy przebadano ponadto znane z literatury cmentarzysko kurhanowe ${ }^{22}$. Prace terenowe, obejmujące prospekcję geofizyczną, pomiary wysokościowe oraz badania powierzchniowe, zrealizowano we współpracy z uniwersytetem w Kilonii. Przyniosły one rozpoznanie zasięgu osad oraz dokładnej lokalizacji, rozmiarów i stanu zachowania grobów kurhanowych.

\section{PODSUMOWANIE}

Przedstawione powyżej wybrane obszary działania archeologów poznańskich ilustrują ogromny potencjał poznawczy cmentarzysk, możliwy do wykorzystania z zastosowaniem całej gamy współczesnych metod badawczych. Tyczy się to zarówno istniejących wciąż nekropolii, zwłaszcza o własnej formie krajobrazowej, jak i materiałów oraz dokumentacji pochodzącej z dawnych, czasem zapomnianych już badań. Jest to szczególnie ważne w dobie obowiązującej polityki konserwatorskiej, w której wykopaliska postrzegane są jako jedno z zagrożeń dla stanowisk archeologicznych. Niemniej jednak zmusza to do poszukiwania nowych rozwiązań badawczych, w których większy nacisk położony jest na bardziej kompleksowe, nieinwazyjne lub w ograniczonym zakresie inwazyjne rozpoznanie stanowisk czy pojedynczych obiektów archeologicznych, a nawet znacznych fragmentów krajobrazu kulturowego. Bez weryfikacji wykopaliskowej lub choćby odwiertów geologicznych interpretacja danych geofizycznych czy teledetekcyjnych obarczona jest

\footnotetext{
${ }^{21}$ Projekt nr 2013/09/N/HS3/02917, kierowany przez mgr. M. Stróżyka z Muzeum Archeologicznego w Poznaniu. Opiekunem naukowym jest prof. J. Czebreszuk, a wykonawcą mgr M. Cwaliński (obaj z IP UAM).

${ }^{22}$ Np. Ziąbka, Maryniak 1996.
} 
znacznym ryzkiem błędu, dlatego niewskazane jest całkowite odejście od metod inwazyjnych. Choć wydaje się to oczywiste, warto podkreślić, że uzupełnieniem prac terenowych powinny być wnikliwe kwerendy archiwów oraz analiza materiału zabytkowego pochodzącego $\mathrm{z}$ wcześniejszych badań wykopaliskowych. Takie postępowanie wydaje się najlepszą drogą do możliwie kompleksowego poznania wyjątkowej sfery aktywności ludzkiej, jaką było i jest grzebanie i upamiętnianie zmarłych.

\section{BIBLIOGRAFIA}

Asam T., Grupe G., Peters J.

2006 Menschliche Subsistenzstrategien im Neolithikum: Eine Isotopenanalyse bayerischer Skelettfunde, Anthropologischer Anzeiger 64 (1), s. 1-23.

Cwaliński M

$2010 \quad$ Kurhan w kulturze mogitowej. Analiza konstrukcji na podstawie cmentarzysk ze Ślaska $i$ Wielkopolski, Poznań [maszynopis pracy licencjackiej, Biblioteka Instytutu Prahistorii UAM].

2012 Kultura mogitowa po dwóch stronach Sudetów. Próba analizy porównawczej kurhanowego obrzadku pogrzebowego kultur mogiłowych z terenów potudniowo-zachodniej Polski oraz zachodnich Czech, Poznań [maszynopis pracy magisterskiej, Biblioteka Instytutu Prahistorii UAM].

Cwaliński M., Niebieszczański J.

2012 The Tumulus Culture Burial Mounds in Southwestern Poland. Construction of the Barrows and their Place in the Landscape [w:] Collapse or Continuity? Environment and Development of Bronze Age Human Landscapes, red. J. Kneisel, W. Kirleis, M. Dal Corso, N. Taylor, V. Tiedtke, Universitätsforschungen zur Prähistorischen Archäologie 205, Bonn, s. 235-256.

Czebreszuk J.

1996 Społeczności Kujaw w początkach epoki brazu, Poznań.

2001 Schytek neolitu i poczatki epoki brazu w strefie potudniowo-zachodniobałtyckiej (III i początki II tys. przed Chr.). Alternatywny model kultury, Poznań.

Czebreszuk J., Jaeger M., Pospieszny Ł., Cwaliński M., Niebieszczański J., Stróżyk M.

2014a Modelowe badania nieinwazyjne obszarów leśnych - Las Krotoszyn, Fontes Archeologici Posnanienses 49, s. 157-175.

2014b Badania nad krajobrazem kulturowym z epoki brązu na pograniczu śląsko-wielkopolskim [w:] Pamięć krajobrazu, red. B. Frydryczak, Poznań [w druku].

2014c Model non-invasive research in forested areas - The Krotoszyn Forest. From the studies on the transformation of cultural landscape in the prehistory of Greater Poland, Schriftenreihe des Bayerischen Landesamtes für Denkmalpflege [w druku].

Harrison R., Heyd V.

2007 The Transformation of Europe in the Third Millennium BC: the example of 'Le PetitChasseur I + III' (Sion, Valais, Switzerland), Praehistorische Zeitschrift 82, s. 129-214.

Horváth T.

2011 Hajdúnánás-Tedej-Lyukas halom - The Interdisciplinary Survey of a Typical Kurgan from the Great Plain Region: a Case Study (The Revision of the Kurgans From the Terri- 
tory of Hungary) [w:] Kurgan Studies: An environmental archaeological multiproxy study of burial mounds of the Eurasian steppe zone, red. A. Barczy, Á. Pető, BAR International Series 2238, Oxford, s. 71-131.

Horváth T., Dani J., Pető Á., Pospieszny Ł., Svingor É.S.

2013 Multidisciplinary Contributions to the Study of Pit Grave Culture Kurgans of the Great Hungarian Plain [w:] Transition to the Bronze Age: Interregional Interaction and SocioCultural Change at the Beginning of the Third Millennium BC in the Carpathian Basin and Surrounding Regions, red. V.M. Heyd, G. Kulcsár, V. Szeverényi, Budapest, s. $153-179$.

Jaeger M., Pospieszny Ł.

2011a Nieinwazyjne badania weryfikacyjne kurhanów kultury mogiłowej na stanowisku Smoszew 1 (pow. Krotoszyn, woj. wielkopolskie) [Sum.: Non-invasive verifications of barrows of the Tumulus culture on the site Smoszew 1 (Krotoszyn distr., Wielkopolska province)] [w:] Materiaty z konferencji „Kopce neolityczne i z poczatków epoki brązu $w$ świetle nowych i najnowszych badań, red. H. Kowalewska-Marszałek, P. Włodarczak, Kraków, s. 419-434.

2011b Tumulus Culture Barrows in the Polish Lowlands. The Case of the Cemetery in Smoszew [w:] Ancestral Landscapes. Burial Mounds in the Copper and Bronze Ages (Central and Eastern Europe - Balkans - Adriatic, 4th-2nd millenium B.C.), red. E. Borgna, S. Müller Celka, Travaux de la Maison de l'Orient et de la Méditerranée 58, Lyon, s. 97-106.

Jovanović B.

1993 Silver in the Yamna (Pit-Grave) Culture in the Balkans, Journal of Indo-European Studies 21 (3/4), s. 207-214.

Kacsó C. Metzner-Nebelsick C., Nebelsick L.D.

2011 New work at the Late Bronze Age Tumulus Cemetery of Lăpuş in Romania [w:] Ancestral Landscapes. Burial Mounds in the Copper and Bronze Ages (Central and Eastern Europe - Balkans - Adriatic, 4th-2nd millenium B.C.), red. E. Borgna, S. Müller Celka, Travaux de la Maison de l'Orient et de la Méditerranée 58, Lyon, s. 341-354.

Kasprolewicz P.

2013 Zróżnicowanie przestrzenne cech litologicznych, geochemicznych i geomagnetycznych kurhanu kultury mogiłowej w Smoszewie (południowa Wielkopolska), Poznań [maszynopis pracy magisterskiej, Biblioteka Instytutu Prahistorii UAM].

Kneisel J., Jaeger M., Pospieszny Ł., Holst M.K.

2010 Ausgrabungen in Smoszew, gm. Krotoszyn, Großpolen Fpl. 1. Sommer 2009 - Ein mittelbronzezeitlicher Grabhügel, Starigard 2008/2009, s. 39-43.

Kostrzewski J.

1922- Kurhany z II okresu epoki brązowej w okolicy Krotoszyna i Ostrowa, Przegląd

1924 Archeologiczny 2, s. 259-274.

Kristiansen K.

$1998 \quad$ Europe Before History, Cambridge.

Kristiansen K., Larsson T.B.

2005 The Rise of Bronze Age Society. Travels, Transmissions and Transformations, Cambridge.

Lanting J.N., van der Plicht J.

1998 Reservoir effects and apparent 14C-ages, The Journal of Irish Archaeology 9, s. 151-164. Niebieszczański J.

2010 Geomorfologia stanowiska ze starszej epoki brazu w Smoszewie (gm. Krotoszyn, woj. wielkopolskie), Poznań [maszynopis pracy licencjackiej, Biblioteka Instytutu Prahistorii UAM]. 
Pospieszny $€$.

2009 Zwyczaje pogrzebowe spoteczności kultury ceramiki sznurowej w Wielkopolsce i na Kujawach, Poznań.

2012 Praktyki ceremonialne na Niżu w międzyrzeczu Odry $i$ Wisty w III tys. przed Chr., Poznań [maszynopis pracy doktorskiej, Instytut Prahistorii UAM].

2014 Freshwater reservoir effect and the radiocarbon chronology of the cemetery in Zabie, Poland [w druku].

Pospieszny Ł., Sobkowiak-Tabaka I., Frei K.M., Hildebrandt-Radke I., Kowalewska-Marszałek H., Krenz-Niedbała M., Osypińska M., Price D.T., Stróżyk M., Winiarska-Kabacińska M.

2014 Remains of a late Neolithic barrow in Kruszyn. A glimpse of ritual and everyday life practice of the early Corded Ware societies in the Polish Lowland [w przygotowaniu].

Primas M.

1996 Velika Gruda I - Hügelgräber des frühen 3. Jahrtausends v. Chr. Im Ardiagebiet Velika Gruda, Mala Gruda und ihr Kontext, Universitätsforschungen zur Prähistorischen Archäologie 32, Bonn.

Szumotalska A.

2012 Wpływ pradziejowej działalności człowieka na przeksztatcenia pokrywy glebowej na stanowisku archeologicznym $w$ Smoszewie (woj. wielkopolskie), Torun [maszynopis pracy licencjackiej, Biblioteka Instytutu Archeologii UMK].

Ziąbka L., Maryniak B.

1996 Archeologiczny rezerwat kurhanowy w Gliśnicy koło Odolanowa, Kronika Wielkopolski 2 (77), s. 110-112.

\author{
NEOLITHIC AND BRONZE AGE IN CENTRAL EUROPE \\ IN THE LIGHT \\ OF INVESTIGATIONS OF CEMETERIES BY RESEARCHERS FROM POZNAŃ
}

\title{
S u m m a r y
}

Archaeologists from Poznań, from the Laboratory of Bronze Age Mediterranean Archaeology at the Institute of Prehistory of Adam Mickiewicz University, have been involved in a number of projects regarding excavations, geophysical and remote sensing research of barrow cemeteries and isotopic analysis of human remains from the Late Neolithic and Bronze Age cemeteries in Poland and abroad. In cooperation with the Hungarian Academy of Sciences there have been studies conducted on the absolute chronology of the Pit Grave culture (also referred to as Yamnaya culture) in the Hungarian Plain. Human skeletal remains from the Neolithic and Early Bronze Age graves from Poland have been dated with ${ }^{14} \mathrm{C}$ method and analysed on isotopes $\delta^{13} \mathrm{C}, \delta^{15} \mathrm{~N}$, ${ }^{87} \mathrm{Sr} /{ }^{86} \mathrm{Sr}$ and ${ }^{18} \mathrm{O} /{ }^{16} \mathrm{O}$.

These studies have been carried out in the framework of a national and European projects, supervised by the University of Gothenburg. In Lăpuş, Romania, a Middle Bronze Age cemetery was measured in terms of height elevation and geophysics. The project has been supervised by archaeologists from the Ludwig-Maximilians-Universität in Munich. 
In Poland, the airborne laser scanning (ALS), geophysical survey (magnetometry and resistivity) and excavation, accompanied by the archive query, focused on Krotoszyn-Ostrów microregion of the Tumulus culture settlement. The foreign partner has been the Christian-Albrecht University in Kiel.

The activities, characterised briefly above, illustrate significance of the potential of analysis of cemeteries, including archival data from former excavations of the cemeteries, with use of modern research methods.

Translated by Lucyna Leśniak 